\title{
Etiology and outcome of Neonatal Acute Kidney Injury in a Special Care Baby Unit
}

\author{
S Afroz ${ }^{1}$, T Ferdous ${ }^{2}$, M Hanif ${ }^{3}$, M A H Mollah ${ }^{4}$, M Banerjee ${ }^{5}$, T H Khan ${ }^{6}$
}

${ }^{1}$ Dr. Shireen Afroz Associate Professor Dept. of Padiatrics Nephrology BICH \& Dhaka Shishu (Children) Hospital

${ }^{2}$ Dr. Tahmina Ferdous Medical Officer

Dhaka Shishu (Children) Hospital

3 Professor Dr. Mohammed Hanif Prof. of Padiatrics Nephrology BICH \& Dhaka Shishu (Children) Hospital

4 Professor Dr. Md. Abid Hossain Mollah Professor of Padiatrics Dhaka Medical College \& Hospital

${ }^{5}$ Professor Dr. Manisha Banarjee Professor of Neonatalogy Dhaka Medical College \& Hospital

${ }^{6}$ Dr. Tofazzal Hossain Khan Associate Prof. of Neonatalogy Dhaka Medical College \& Hospital

Correspondence

Dr. Shireen Afroz

Associate Professor

Dept. of Padiatrics Nephrology

BICH \& Dhaka Shishu (Children) Hospital email: Safroz16@live.com

\section{Abstract}

Background : The cause of acute kidney injury (AKI) in neonate is multifactorial. The short-term outcome of AKI in newborns is highly dependent on the underlying etiology, the condition of other organs, and the facilities for renal replacement therapy.

Objective : The aims of the present study were to find out the etiology and immediate outcome of AKI in neonate.

Methodology : This observational study was done over a period of six months, at special care baby unit (SCABU) in Dhaka Medical College Hospital (DMCH). Neonates (aged 3-28 days) admitted in SCABU, who had AKI were the study population. Among them 44 neonates with AKI were included purposivly. AKI was diagnosed and classified by pediatric RIFLE (pRIFLE) staging criteria. Etiology of AKI was find out by dividing pre renal, renal and post renal cause of AKI. All neonates were treated conservatively and with intermittent peritoneal dialysis (IPD) as needed. Immediate hospital outcome was determined by improved with normal renal functions; improved with impaired renal functions and death.

Result : The diagnosis based on estimated creatinine clearance (eCCL) criteria of pRIFLE showed that $43.2 \%$ neonates were at risk (R) stage, $22.7 \%$ were at injury (I) stage and $34.1 \%$ of neonates were at Failure (F) stage of AKI. Among 44 neonates 21 were male and 23 were female. Pre renal cause of AKI is predominant in this series. More than two-thirds (68.2\%) of the neonates experienced perinatal asphyxia stage-II and III and $52.3 \%$ were exposed to meconium stained liquor during delivery. Septicemia with shock, history of aminoglycoside use were reported to be $59.1 \%, 52.3 \%$ respectively. Post renal cause was found in $16 \%$ neonates, like obstructive uropathy due to posterior urethral valve, exstrophy bladder and cloacal exstrophy. Neonate at Failure stage of AKI $(n=15)$ had a significantly longer stay at SCABU $(p<0.001)$. Multiorgan failure was found to be significantly higher in failure group $(p=0.026)$. Majority of the failure group needed dialysis ( $p<0.001$ ). Most of the neonate at risk and injury stage was improved with normal renal functions. The resolution from AKI was almost similar among the groups $(p=0.885)$. The mortality was progressively higher from Risk to Failure Groups $(p=0.106)$. Overall $27 \%$ of the neonates diagnosed as AKI died from this illness, $57 \%$ improved with normal renal function and $16 \%$ improved with impaired renal function.

Conclusion : The study concluded that perinatal asphyxia, septicemia with shock and use of aminoglycosides were the commonest cause of AKI in neonate. The mortality was higher in Failure group.

Key words : Neonatal AKI, Etiology, Outcome, pRIFLE

Northern International Medical College Journal Vol. 7 No. 02 January 2016, Page 127-130

\section{Introduction}

Fluid, electrolyte and metabolic abnormalities are the commonest derangements encountered in ill neonates with impaired renal function. The cause of AKI is multifactorial, and usually there are more than one factors contribute to the development of neonatal $\mathrm{AKI}^{1}$. The shortterm outcome of AKI in newborn is highly dependent on the underlying etiology, the condition of other organs, and the facilities for renal replacement therapy. Mortality is more frequent and morbidity is much worse in neonates with multiorgan failure ${ }^{2}$. Therefore, high index of suspicion, prompt recognition and thorough understanding of etiology of AKI is necessary to ensure their correction and improving neonatal outcome.

The aims of the present study were to find out the etiology and outcome of neonates with AKI diagnosed and classified by pRIFLE staging criteria after being treated conservatively and by peritoneal dialysis.

\section{Methodology}

This observational study was carried out in the SCABU of Dhaka Medical College Hospital, Dhaka from October' 2013 to March' 2014. Prior permission was taken for this study from the Ethical Committee of Dhaka Medical College Hospital, Dhaka, Bangladesh. Written informed consent was obtained from each 
parents/attendants. All measure was taken to keep the anonymity of the participating subjects. Neonates (aged 3-28 days) admitted in SCABU and fulfilled the predefined eligibility criteria of AKI according to $p$ RIFLE criteria ${ }^{3}$ were the study population. Among them 44 neonates with AKI were included purposively in the study.

AKI was suspected when urinary output was reduced $<0.5$ $\mathrm{ml} / \mathrm{kg} / \mathrm{hr}$ and classified into risk(R), injury (I) and failure (F) stages by using PRIFLE criteria3. Patients with Congenital anomalies other than urinary tract and parents unwilling to allow their neonates to participate were excluded.

Urine was collected by urine collecting adhesive bag, and was recorded as $\mathrm{ml} / \mathrm{per} \mathrm{Kg}$ per hour in follow up sheets. After $3^{\text {rd }}$ day of admission when urinary output was reduced then $2 \mathrm{ml}$ of blood sample was taken for serum creatinine criteria of AKI staging. Base line serum creatinine was considered $0.3 \mathrm{mg} / \mathrm{dl}^{\mathrm{r}}$ .Serum creatinine was noted when raised $>0.3 \mathrm{mg} / \mathrm{dl}$ or raised 1.5-3 folds from the base line. By Schwartz formula\{i,e $(\mathrm{eCCl}=\mathrm{ht}(\mathrm{cm}) \times \mathrm{k} / \mathrm{S}$.creatinine $)$ where $\mathrm{k}$ for preterm $=0.27$ and for term $=0.37\}$ estimated creatinine clearance $(\mathrm{eCCl})$ was calculated. According to acute kidney injury classification (pRIFLE criteria), neonate with impaired renal function were classified as Risk, Injury, Failure group on the basis of eCCL and urine output criteria. All patients were treated with supportive care and intermittent peritoneal dialysis as needed. Data were collected from the patients by interview of their guardians, clinical examination and through the records of laboratory findings using a questionnaire containing the variables of interest.

$\begin{array}{lll}\text { Paediatric RIFLE criteria of AKI staging } & & \\ & \begin{array}{l}\text { Estimated creatinine } \\ \text { clearance (eCCL) }\end{array} & \text { Urine output } \\ \text { Risk(stage-1) } & \text { eCCl decreased by } 25 \% & <0.5 \mathrm{ml} / \mathrm{kg} / \mathrm{hr} \text { for } 8 \mathrm{hrs} \\ \text { Injury (stage-2) } & \text { eCCl decreased by } 50 \% & <0.5 \mathrm{ml} / \mathrm{kg} / \mathrm{hr} \text { for } 16 \mathrm{hrs} \\ \text { Failure(stage-3) } & \text { eCCl decreased by } 75 \% & <0.3 \mathrm{ml} / \mathrm{kg} / \mathrm{hr} 24 \mathrm{hrs} \text { or } \\ \text { anuria for } 12 \text { hrs } & & \\ \text { Loss (stage-4) } & \text { Persistent failure for }>4 \text { weeks } & \\ \text { End-stage (stage-5) } & \text { Persistent failure }>3 \text { month }\end{array}$

\section{Statistical analysis}

Using computer software SPSS -16, data were processed and analyzed. The test statistics used to analyze the data were descriptive statistics, Chi-square $\left({ }^{2}\right)$ test, ANOVA. Level of significance was considered with $p<0.05$.

\section{Result}

A total 44 neonates (from $3-28$ days) with AKI were included in the study. The findings of the study obtained from data analysis are presented below:
Table I : Demographic profile among the study populations $(n=44)$

$\begin{array}{lcc}\text { Variables } & \text { No of case with AKI } & \text { (\%) } \\ \text { Age } & & \\ <7 \text { days } & 28 & 64 \\ 8-14 \text { days } & 11 & 25 \\ 15-21 \text { days } & 3 & 6.8 \\ >21 \text { days } & 2 & 4.5 \\ \text { Sex } & & \\ \text { Male } & 21 & 48 \\ \text { Female } & 23 & 52 \\ \text { Birth weight (gm) } & & \\ \text { 1000-1500 } & 2 & 45 \\ >1500-2500 & 10 & 23 \\ >2500 & 32 & 72.5 \\ \text { Gestational age } & & \\ \text { Pre term } & 11 & 25 \\ \text { Term } & 33 & 75\end{array}$

Neonates of $<7$ days old comprised the main bulk (64\%) of the study population Among 44 neonates 21 were male and 23 were female. Majority $(n=32)$ were with normal birth weight. Term baby were predominant $(n=33)$. Prematurity was found in $25 \%$ cases. (Table I)

\section{Table II. Causes AKI in study cases $\left(n=44^{*}\right)$}

Perinatal/Neonatal characteristic

No $\quad \%$

Prerenal

Perinatal asphyxia stage II \& stage III $\quad 30 \quad 68.2$

Meconium stained liquor $\quad 23 \quad 52.3$

$\begin{array}{lll}\text { Septicemia with shock } & 26 & 59.1\end{array}$

Early onset neonatal sepsis ( EONS $=18$ )

Late onset neonatal sepsis LONS $=8$ )

Prematurity $\quad 11 \quad 25.0$

Diarrhea $\quad 2 \quad 4.5$

$\begin{array}{lll}\text { Vomiting } & 4 & 9.1\end{array}$

Renal

Amino glycosides used during onset of AKI 23

Post-renal

Hydronephrosis with posterior urethral valve $\quad 1 \quad 2.3$

Exstrophy of bladder $\quad 4 \quad 9.1$

Cloacal exstrophy $\quad 2 \quad 4.5$

* Total number will not correspond to $100 \%$, for multiple responses

More than two-thirds (68.2\%) of the neonates experienced perinatal asphyxia stage-II and III and then who were exposed to meconium stained liquor during delivery $52.3 \%$. Prematurity was found in $11(25 \%)$ cases. Septicemia with shock and history of amino glycosides used in neonates were reported to be $59.1 \%$ (EONS $40.9 \%$ and LONS $18.2 \%$ ) and $52.3 \%$ respectively (Table-II). 
Distribution of neonates by their rate of urine output is shown in Table VI. Of the 44 neonates, $15(34.1 \%)$ passed urine $(<0.5$ $\mathrm{ml} / \mathrm{kg} / \mathrm{hr}$ ) in 8 hours (Risk) and $9(20.5 \%)$ passed the same amount in 16 hours (Injury). About $30 \%$ of the neonates passed $<0.3 \mathrm{ml} / \mathrm{kg} / \mathrm{hr}$ of urine in 24 hours (Failure) and about $16 \%$ did not pass any urine in 12 hours (Failure) (Table III).

Table III : Distribution of neonatal AKI by urine output criteria of pRIFLE

Urine output $(\mathrm{ml} / \mathrm{kg} / \mathrm{hr})$

Time interval

$\begin{array}{lcccc} & \begin{array}{c}8 \text { hours } \\ \text { (no } \%)\end{array} & \begin{array}{c}12 \text { hours } \\ \text { (no \%) }\end{array} & \begin{array}{c}16 \text { hours } \\ \text { (no } \%)\end{array} & \begin{array}{c}24 \text { hours } \\ \text { (no \%) }\end{array} \\ <0.5 \mathrm{ml} / \mathrm{kg} / \mathrm{hr} & 15(34.1) & --- & 9(20.5) & --- \\ <0.3 \mathrm{ml} / \mathrm{kg} / \mathrm{hr} & --- & -- & -- & 13(29.5) \\ \text { Anuria } & --- & 7(15.9) & --- & ---\end{array}$

The diagnosis based on eCCL criteria of pRIFLE shows that $43.2 \%$ neonates were at risk of acute kidney injury, $22.7 \%$ have had already injured and $34.1 \%$ had kidney failure. (Table IV)

Table IV : Distribution of neonatal AKI by estimated creatinine clearance $(e C C L)$ of pRIFLE criteria $(n=44)$

eCCL pRIFLE classification

No

$\%$

Decreased by $25 \%$ Risk

19

43.2

Decreased by $50 \%$ Injury

10

22.7

Decreased $75 \%$

Failure

15

34.1

There was no difference between Risk and Injury in terms of hospital stay at SCABU. However, Failure group had a significantly longer stay compared to Risk and Injury Group ( $p<$ 0.001). Multiorgan failure was found to be higher in failure group compared to other two groups $(p=0.026)$. Most of the failure group needed dialysis as compared to the Risk and Injury group ( $p<0.001)$. The resolution from AKI was almost similar among the groups $(p=0.885)$. The mortality was progressively higher from Risk to Failure Groups $(p=0.106)$ (Table V).

Table V : Outcome of different classes of AKI by pRIFLE criteria $(n=44)$

Outcome variables

$\begin{array}{cllr} & \text { pRIFLE } & \text { p-value } \\ \text { Risk } & \text { Injury } & \text { Failure } \\ (n=19) & (n=10) & (n=15)\end{array}$

Duration of stay at SCABU* $4.7 \pm 0.54 .8 \pm 0.412 .1 \pm 7.9<0.001$

$\begin{array}{lllll}\text { Multi organ failure }^{\#} & 1(5.6) & 4(44.4) & 7(41.2) & 0.026\end{array}$

Dialysis needed $^{\#} \quad 0(0.0) \quad 0(0.0) \quad 15(88.2)<0.001$

$\begin{array}{lllll}\text { Resolution from AKI }^{\#} & 7(38.9) & 4(44.4) & 8(47.1) & 0.885\end{array}$

$\begin{array}{lllll}\text { Mortality }{ }^{\#} & 2(11.1) & 3(33.3) & 7(41.2) & 0.106\end{array}$

*Data were analysed using ANOVA statistics and were presented as mean \pm SD. \# Data were analysed using Chi-square Test $\left(\mathrm{x}^{2}\right)$ and were presented as $\mathrm{n}(\%)$.
Table VI : Outcome of newborn with AKI $(n=44)$

$\begin{array}{lccc}\text { pRIFLE stages } & \begin{array}{c}\text { Improved with } \\ \text { normal renal function }\end{array} & \begin{array}{c}\text { Improved with } \\ \text { impaired renal function }\end{array} & \text { Death } \\ \text { Risk }=19 & 17 & 0 & 2 \\ \text { Injury }=10 & 7 & 0 & 3 \\ \text { Failure }=15 & 1 & 7 & 7 \\ \text { Total }=44 & 25(57 \%) & 7(16 \%) & 12(27 \%)\end{array}$

Overall $27 \%$ of the neonates diagnosed as AKI died of the disease, 57\% improved with normal renal function and 16\% improved with impaired renal function (table-VI).

\section{Discussion}

The aims of the present study were to find out the etiology and outcome of neonates with AKI diagnosed and classified by pRIFLE staging criteria. The incidence of AKI varies according to the population studied, the level of attention of the hospital center, and the country's level of development ${ }^{4}$ Presently, AKI classify with scales of severity or stages by the pRIFLE Scale, which was validated in 2007. ${ }^{3}$ It has been shown that the incidence of AKI increases when applying the pRIFLE Scale. ${ }^{3,4,5}$ Rovetto et al reported the incidence of AKI in the NICU is 16 times higher than in wards, which shows that the risk of AKI increases as the patient is more critical and associated with multiorgan dysfunctions. ${ }^{6}$

In the present study neonates with AKI had no difference in terms of age, sex and birth weight. The neonate of 7 days old comprised the main bulk (64\%). More than two third (68.2)\% of the neonates experienced perinatal asphyxia stage II and stage III, most commonest prerenal cause of AKI. ${ }^{7}$ Moreover second risk group is septicemia (59\%)). In other studies ${ }^{1,2,7-10}$ similar to this study, there was no difference in age, sex, birth weight and outcome of AKI.

In different study main of causes of AKI was found as septicemia, hypovolemia, hypotension, multiorgan failure, intravascular volume depletion, intraventricular hemorrhage, uses of phototherapy due to increased nitric oxide which causes vasodilatation, hypernatremic dehydration, different nephrotoxic drug users. ${ }^{1,2,7-10-11}$ In this series, AKI has been observed in a higher number of neonates who had treated with aminoglycoside drugs. Higher percentage (27\%) of the neonates diagnosed as acute kidney failure by pRIFLE criteria had died of the disease. Previous study report also suggested that longest NICU stay with intervention needed in Failure group associated with significantly higher rate of mortality. ${ }_{1}, 2,7,9,11,12,14,15$

In the present study the outcome of AKI in neonates predicted by PRIFLE criteria showed significantly higher number of neonates in failure group in respect to hospital stay at SCABU. Multiorgan failure was found to be significantly higher in this group. All neonates of the failure group was needed dialysis. The mortality was also increasingly higher in failure groups. 
Majority of the neonates in risk and injury group were improved with normal renal functions.

And none of them needed IPD. Several previous study reports has also shown similar outcome in failure stage. ${ }^{4,15-17}$

\section{Conclusison}

The study concluded that perinatal asphyxia, septicemia with shock and use of aminoglycosides were the commonest cause of AKI in neonate. The mortality was higher in Failure group. Multiorgan failure was an important factor for worst outcome.

\section{References}

1. Cuzzolin L, Fanos V, Pinna B. Postnatal renal function in preterm newborns. a role of diseases, drugs and therapeutic interventions Pediatr Nephrol 2006;21:931-8.

2. Nouri $\mathrm{S}$, Mahdhaoui $\mathrm{N}$, Beizig $\mathrm{S}$. Acute renal failure in full term neonates with perinatal asphyxia. Arch Pediatr 2008; 15:229-35.

3. Akcan-Arikan A, Zappitelli M, Loftis LL. Modified RIFLE criteria in critically ill children with acute kidney injury, Kidney Int 2007; 71: 1028-35.

4. Phan V, Brophy P, Fleming G. Acute renal Failure: prevention, causes, and investigation. In: Geary $D$, Schaefer $F$ (eds). Comprehensive pediatric nephrology. Philadelphia: Mosby, Elsevier; 2008.p 607-27.

5. David Askenazi,. Evaluation and Management of Critically III Children with Acute Kidney Injury. Curr Opin Pediatr 2011; 23:201-207*

6. Rovetto C, Julián A, Cardona S, Andrés F, Juan F, de Castaño I. Acute kidney injury applying pRifle scale in Children of Hospital Universitario del Valle in Cali, Colombia: clinical features, management and evolution. Colombia Médica 2012; 43(3):200-04.

7. RN Srivastava, Arvind Bagga. Acute kidney injury, Paediatric Nephrology $.5^{\text {th }}$ edition Jaypee Brother Medical Published New Delhi 2011; .235-236.

8. Subramanian S, Agarwal R, Deorari AK, Paul VK, Bagga A. Acute renal failure in neonates. Indian J Pediatr 2008;75:385-91.

9. Zappitelli M, Bernier PL, Saczkowski RS, Tchevenkov CI, Gottesman R, Dancea $A$, et al. A small post-operative rise in serum creatinine predicts acute kidney injury in children underogoing cardiac surgery. Kidney Int. 2009; 76: 885-92.

10. Plotz FB, bouma Ab van Wijk JA, Kneyber MC,bokenkamp A. Pediatric acute kidney injury in the ICU: an independent evaluation of pRIFLE criteria. Intensive Care Med. 2008; 34: 1713-7.

11. Sharon Phillips Andreloi. Acute kidney injury in critically ill newborn. Pediatr Nephroogy 2009;24:253-263.

12. Mathur NB, Agarwal HS, Maria A. Acute renal failure in neonatal sepsis. Indian J Pediatr 2006;73:499-502.

13. Koraikar, Ambalavanan N , Levitan EB .Acute kidney injury reduces survival in very low birth weight infants. Pediatr Res 2011; 69: 354- 58.

14. Fernandez C, Lopez-Herce J, Flores JC, Galaviz D, Rupérez M, Brandstrup KB, Bustinza A. Prognosis in critically ill children requiring continuous renal replacement therapy. Pediatr Nephrol 2005; 20:1473-1477.

15. Hsu C W, Symons JM. Acute kidney injury: can we improve prognosis? Pediatr Nephrol. 2010; 25: 2401-12.

16. Devarajan P. Emerging biomarkers of AKI. Contrib Nephrol 2007; 156:203-312.

17. Bagga A, Bakkaloglu A, Devarajan P, Mehta RL, Kellum JA, Shah SV, Molitoris BA, Ronco C, Warnock DG, Joannidis M, Levin A, Acute Kidney Injury Network. Improving outcomes from acute kidney injury: report of an initiative. Pediatr Nephrol 2007; 22:1655-1658. 